Check for updates

Cite this: RSC Adv., 2017, 7, 32682

Received 15th May 2017

Accepted 22nd June 2017

DOI: 10.1039/c7ra05458k

rsc.li/rsc-advances

\section{Enhanced mechanical properties of Nylon6 nanocomposites containing pristine $\alpha$-zirconium phosphate nanoplatelets of various sizes by melt- compounding}

\begin{abstract}
He Zhang, Lei Chen, Xiao Han, Feng Jiang, Haoyang Sun and Dazhi Sun (DD*
Nylon6 nanocomposites containing pristine layered $\alpha$-zirconium phosphate (ZrP) nanoplatelets of various sizes have been fabricated by a simple and direct melt-compounding method without adding intercalation or exfoliation agents. Owing to the excellent compatibility between the nanofillers and Nylon6, the pristine ZrP nanoplatelet nanocrystallites were well dispersed and homogeneously distributed into the polymer matrices during the melt processing, but still maintained their original layered state as observed by scanning electron microscopy and X-ray diffraction. Tensile testing and dynamic mechanical analysis on the Nylon6/ZrP nanocomposites illustrate that the size and concentration of the pristine ZrP nanoplatelets have a profound effect on the mechanical properties of such prepared polymer nanocomposites. The improvement of the mechanical reinforcement for the Nylon6 nanocomposites does not show a steady increase with the increase in the size and concentration of the embedded pristine ZrP nanoplatelets, but displays the maximum for the pristine ZrP nanoplatelets with a size ranging from $600 \mathrm{~nm}$ to $800 \mathrm{~nm}$ at a concentration of $\sim 3.0-5.0 \%$ in the polymer matrices. The mechanisms that are responsible for the mechanical reinforcement of thermoplastic polymer matrices by the embedded pristine ZrP nanoplatelets, as well as their comparisons with corresponding epoxy nanocomposites, are also discussed.
\end{abstract}

\section{Introduction}

Polymer nanocomposites ${ }^{1}$ containing well-dispersed inorganic nanofillers exhibit significantly reinforced mechanical performance and excellent physical properties. ${ }^{2}$ Different types of nanofillers that have been frequently embedded into various polymer matrices include 0-dimensional spherical/quasispherical nanoparticles, 1-dimensional nanotubes/nanowires/ nanorods, and 2-dimensional nanoplatelets/nanosheets. Among the varieties of polymer nanocomposites, polymer nanocomposites containing inorganic nanoplatelets, especially polymer/layered silicate nanocomposites ${ }^{3-10}$ have attracted probably the broadest attention in both fundamental research and industrial applications because of their excellent mechanical properties, ${ }^{\mathbf{1 1}}$ thermal stability, ${ }^{\mathbf{1 2}}$ barrier performance, ${ }^{\mathbf{1 3}}$ flame resistance ${ }^{\mathbf{1 4 - 1 6}}$ and so on. More importantly, the clay MMT (montmorillonite) is cheap and can be incorporated into various polymers, i.e. thermoplastic Nylons, by melt processing, which makes such polymer/clay nanocomposites suitable for industry-scale fabrications at a low cost.

Center for Nanoimprinting Technology, Department of Materials Science and Engineering, Southern University of Science and Technology, Shenzhen 518055, China.E-mail:sundz@sustc.edu.cn
In the past decade, numerous efforts have been focused on the enhancements of the physical and mechanical properties ${ }^{\mathbf{1 7}}$ for polymer/clay, ${ }^{\mathbf{1 8 , 1 9}}$ i.e. Nylon6/MMT, ${ }^{\mathbf{2 0}-22}$ epoxy/clay, ${ }^{\mathbf{2 3 - 2 5}}$ nanocomposites, and most of such research has concentrated on achieving a high degree of exfoliation and a better dispersion of $\mathrm{MMT}^{\mathbf{2 6 , 2 7}}$ or improving the interfacial adhesion of clays to the polymer matrices via surface modifications. ${ }^{28,29}$ However, the improvements of the physical and mechanical properties of such polymer nanocomposites are not only limited to the above influences, but also determined by many other factors including size, shape and aspect ratio of the clays. ${ }^{30}$ The relevant modeling work ${ }^{31}$ has confirmed the importance of these factors on the properties of polymer nanocomposites, but there are still lack of the experimental data reports on how the size affects the mechanical properties of polymer nanocomposites because of the limited aspect ratios for the natural clays.

As compared to the natural clays, synthetic layered $\alpha$-zirconium phosphate (ZrP) nanoplatelets have advantages such as defined chemical structure, high purity, ease to control the size and aspect ratio, large ion-exchange capacity, and high activity for surface and interlayer modifications, ${ }^{32-34}$ and therefore they have been utilized as a model clay to invest the nanofiller effects on the properties of polymer nanocomposites. Epoxy nanocomposites containing ZrP nanoplatelets with variations in size, 
aspect ratio, dispersion state, surface and interlayer functionalities, and so on have been prepared through solution mixing to investigate the structure-property relationships in thermoset/ZrP nanocomposites. However, such systematical studies have not been realized in thermoplastic polymers. Although ZrP nanoplatelets have shown great potentials on improving the flame retardant properties of various thermoplastic matrices, ${ }^{35}$ the experimental reports regarding their effects on the mechanical properties of such polymer matrices are still lacking. Moreover, solution mixing is a good processing method to prepare polymer nanocomposites with well dispersed nanofillers such as epoxy/ ZrP nanoplatelets nanocomposites, however, for most of the engineering plastics, i.e. Nylon, it is better to adapt the melt mixing procedures from the industrial processing so that reinforced polymer nanocomposites with $\mathrm{ZrP}$ nanoplatelets can be fabricated in large quantities at low cost.

Herein, we have prepared Nylon6 nanocomposites containing pristine ZrP nanoplatelets with various sizes by a melt compounding method without using any intercalation/exfoliation agents. Although the addition of surfactant molecules such as amines could lead to a better dispersion and even exfoliation of the layered nanoplatelets into the polymer matrices which is similar to the polymer/clay nanocomposites, such procedure would inevitably cause additional processing steps and cost to the practical applications, and in some cases even degrade the physical properties of the polymer matrices. Therefore, the current work is aimed to provide a simple and easy to scale-up method that directly incorporates the pristine ZrP nanoplatelets into Nylon6 matrices through melt compounding. The mechanical properties characterized by tensile testing and dynamic mechanical analysis are provided. In our subsequent research, we will continue to study the exfoliation and modifications of $\mathrm{ZrP}$ nanoplatelets in Nylon and other engineering thermoplastics.

\section{Experimental}

\subsection{Materials}

Nylon-6 pellets (1013B) used in this study were purchased form Ube Industries company in Japan. Zirconyl chloride $\left(\mathrm{ZrOCl}_{2}\right.$ $\cdot 8 \mathrm{H}_{2} \mathrm{O}, 98 \%$, Aladdin $)$ and phosphoric acid $\left(\mathrm{H}_{3} \mathrm{PO}_{4}, 85 \%\right.$, Aladdin) were used to synthesize the pristine $\mathrm{ZrP}$ nanoplatelets.

\subsection{Fabrication}

2.2.1. Synthesis of $\mathrm{ZrP}$ nanoplatelets. $\mathrm{ZrP}$ nanoplatelets were synthesized by the hydrothermal method. ${ }^{36}$ A sample of $15.0 \mathrm{~g} \mathrm{ZrOCl}_{2} \cdot 8 \mathrm{H}_{2} \mathrm{O}$ was mixed with $150 \mathrm{~mL}$ 3.0/6.0/9.0 $\mathrm{M} \mathrm{H}_{3} \mathrm{PO}_{4}$ respectively and then sealed into a Teflon-lined pressure vessel and heated at $200{ }^{\circ} \mathrm{C}$ for $5 \mathrm{~h}$. After the reaction, these respective samples were washed and collected by centrifuging three times. Then the samples were dried at $65^{\circ} \mathrm{C}$ for $24 \mathrm{~h}$ and ground with a mortar and pestle into fine powders. The final products were identified as $3 \mathrm{MZrP}, 6 \mathrm{MZrP}$, 9MZrP, respectively, according to the various concentration of $\mathrm{H}_{3} \mathrm{PO}_{4}$.

2.2.2. Preparation of Nylon6 nanocomposite containing ZrP nanoplatelets. According to proportions listed in Table 1, the Nylon6/ZrP nanocomposites were manufactured by mixing
Table 1 Descriptions of the neat Nylon and Nylon nanocomposite filled with $\mathrm{ZrP}$ nanoplatelets ${ }^{a}$

\begin{tabular}{lll}
\hline Samples & Nylon6 $(\mathrm{g})$ & $\mathrm{ZrP}(\mathrm{g})$ \\
\hline Neat Nylon6 & 50 & 0 \\
$\chi$ M 1.0\% ZrP & 50 & 0.5 \\
$\chi$ M 3.0\% ZrP & 50 & 1.5 \\
$\chi$ M 5.0\% ZrP & 50 & 2.5
\end{tabular}

${ }^{a}$ Note: $\chi \mathrm{M}(\chi=3,6,9)$ represents the concentration of phosphoric acid; $\chi \mathrm{M} 1 \% \mathrm{ZrP}$ means that $\chi \mathrm{M} \mathrm{ZrP}$ nanoplatelets accounts for $1.0 \%$ of the whole amount of neat Nylon6.

neat Nylon6 and different sizes and amount of ZrP nanoplatelets via a melt-compounding method using a Haake Rheomix OS mixer. The mixture temperature was set at $215{ }^{\circ} \mathrm{C}$ with a screw speed of $50 \mathrm{rpm}$ for $11 \mathrm{~min}$ and then $80 \mathrm{rpm}$ for $3 \mathrm{~min}$. These samples were crushed and dried at $60{ }^{\circ} \mathrm{C}$ for $24 \mathrm{~h}$. Then, the extruded pellets were injection-molded into standard tensile (ASTM D638-10) bars using a Haake MiniJet II injection molding machine. The barrel temperature was set at $270{ }^{\circ} \mathrm{C}$ and the mold temperature was fixed at $65^{\circ} \mathrm{C}$. An injection pressure of 70 bar and a holding pressure of 65 bar were used for $10 \mathrm{~s}$ and $3 \mathrm{~s}$, respectively.

\subsection{Characterization}

2.3.1. Structures of $\mathrm{ZrP}$ nanoplatelets and Nylon nanocomposites. The morphologies of various sizes of $\mathrm{ZrP}$ nanoplatelets and their dispersion in the Nylon6 nanocomposites were examined using a scanning electron microscope (SEM VEGA 3 LMH, Tescan Co. Ltd) at an accelerating voltage of 20.0 and $10.0 \mathrm{kV}$ respectively. The samples of pure $\mathrm{ZrP}$ nanoplatelets and the fractured surfaces of the composites were spray with gold prior to observation.

The crystalline phases of these samples were analysed by an $\mathrm{X}$-ray diffractometer (XRD, Bruker D8) with $\mathrm{Cu} \mathrm{K} \alpha$ radiation $(\lambda=$ $0.154 \mathrm{~nm}$ ) with operating conditions of $40 \mathrm{kV}$.

2.3.2. Mechanical properties of nanocomposites. The tensile tests were carried out using an Instron legend 2367 material testing system (model D638-10) at room temperature with gauge length of $36 \mathrm{~mm}$ and crossed speed of $20 \mathrm{~mm} \mathrm{~min}^{-1}$. An Instron strain gauge extensometer (10 $\mathrm{mm}$ gauge) was used to improve the accuracy of testing data and the final results were all gained based on the average of five samples.

Dynamical mechanical analysis (DMA) was conducted under an auto tension model with a Perkin Elmer DMA 8000 system at temperatures ranging from $-50{ }^{\circ} \mathrm{C}$ to $200{ }^{\circ} \mathrm{C}$ and a frequency of $1 \mathrm{~Hz}$ and a heating rate of $2{ }^{\circ} \mathrm{C} \mathrm{min}^{-1}$. The glass transition temperatures $\left(T_{\mathrm{g}}\right)$ were determined based on the maximum temperatures on the curves of $\tan \delta$ versus temperature.

\section{Results and discussion}

\subsection{Characterizations of ZrP nanoplatelets and Nylon6 nanocomposites}

The morphologies and microstructures of the pristine ZrP nanoplatelets and representative Nylon6 nanocomposites 
containing $5 \mathrm{wt} \%$ of various pristine $\mathrm{ZrP}$ nanoplatelets characterized by SEM are shown in Fig. 1. Crystalline ZrP nanoplatelets were first synthesized by A. Clearfield et al. through a refluxing method, ${ }^{37}$ which, later on, has been well recognized and widely used to prepare layered ZrP nanoplatelets for various applications. In this study, we prepared the pristine ZrP nanoplatelets with various sizes via a hydrothermal method modified by Luyi Sun et al. ${ }^{34}$ It's clear from Fig. 1a-c that with increasing the concentration of phosphoric acid from $3 \mathrm{M}$ to $6 \mathrm{M}$ to $9 \mathrm{M}$ in the hydrothermal reactions, the size of the pristine ZrP nanoplatelets increases gradually. The diameters of $3 \mathrm{MZrP}, 6 \mathrm{MZrP}$ and 9MZrP are approximately 400-600 nm, 600-800 $\mathrm{nm}$ and 800-1000 nm, respectively, which agree with the literature reports. $^{36,38}$ As compared to the $6 \mathrm{MZrP}$ and $9 \mathrm{MZrP}$ nanoplatelets, the $3 \mathrm{MZrP}$ nanoplatelets were easier to agglomerate owing to their smaller size and larger surface area.

To verify the dispersion of the pristine ZrP nanoplatelets in Nylon6 matrices by melting compounding without using any intercalation and exfoliation agents, only the SEM images of the Nylon6 nanocomposites with the highest nanofiller concentration are shown. As observed in Fig. $1 \mathrm{~d}-\mathrm{f}$, the majority of the incorporated $\mathrm{ZrP}$ nanoplatelets maintained their pristine structure and in the Nylon6 matrices after melt compounding.

The structure of various pristine $\mathrm{ZrP}$ nanoplatelets and Nylon6/ZrP nanocomposites is also confirmed by X-ray diffraction (XRD) as shown in Fig. 2. In the XRD patterns, the diffraction peaks of the pristine $\mathrm{ZrP}$ nanoplatelets were similar to the literature report. ${ }^{36}$ The strong diffraction peak at $11.7^{\circ}$ for all the ZrP-related samples in the XRD patterns clearly

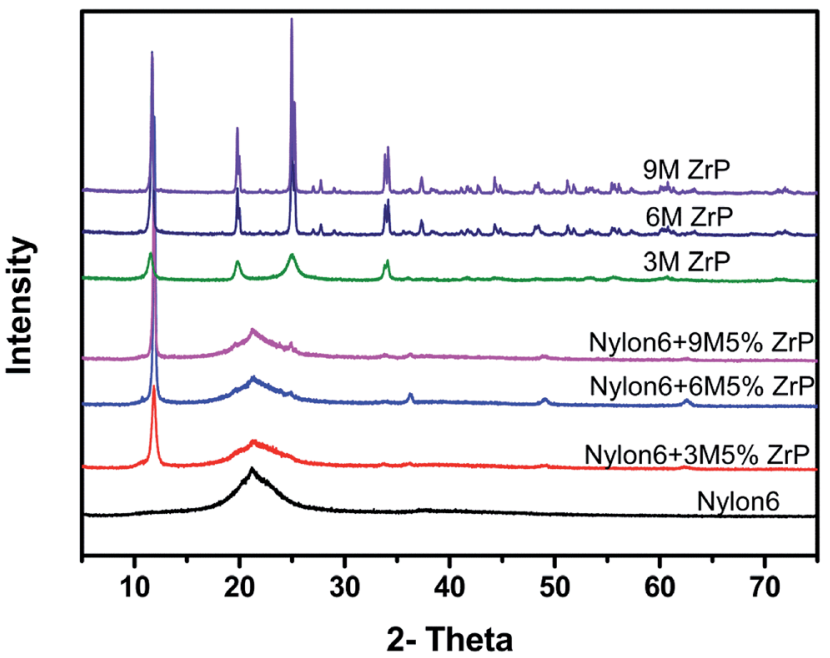

Fig. 2 XRD patterns of Nylon6, different aspect ratios of ZrP nanoplatelets and Nylon6/ZrP nanocomposites.

illustrates that all the $\mathrm{ZrP}$ nanoplatelets with various sizes remain the same crystalline form before and after being incorporated into Nylon6 matrices by melt compounding, which agrees with the SEM observations shown in Fig. 1. The characterization results for SEM images and XRD patterns indicate that the melt mixing process without the aid of any surfactant cannot, as expected, result in the interaction or exfoliation of layered ZrP nanoplatelets in polymer matrices.

The excellent dispersion of the pristine ZrP nanoplatelets in Nylon6 without using any surfactant is attributed to the good
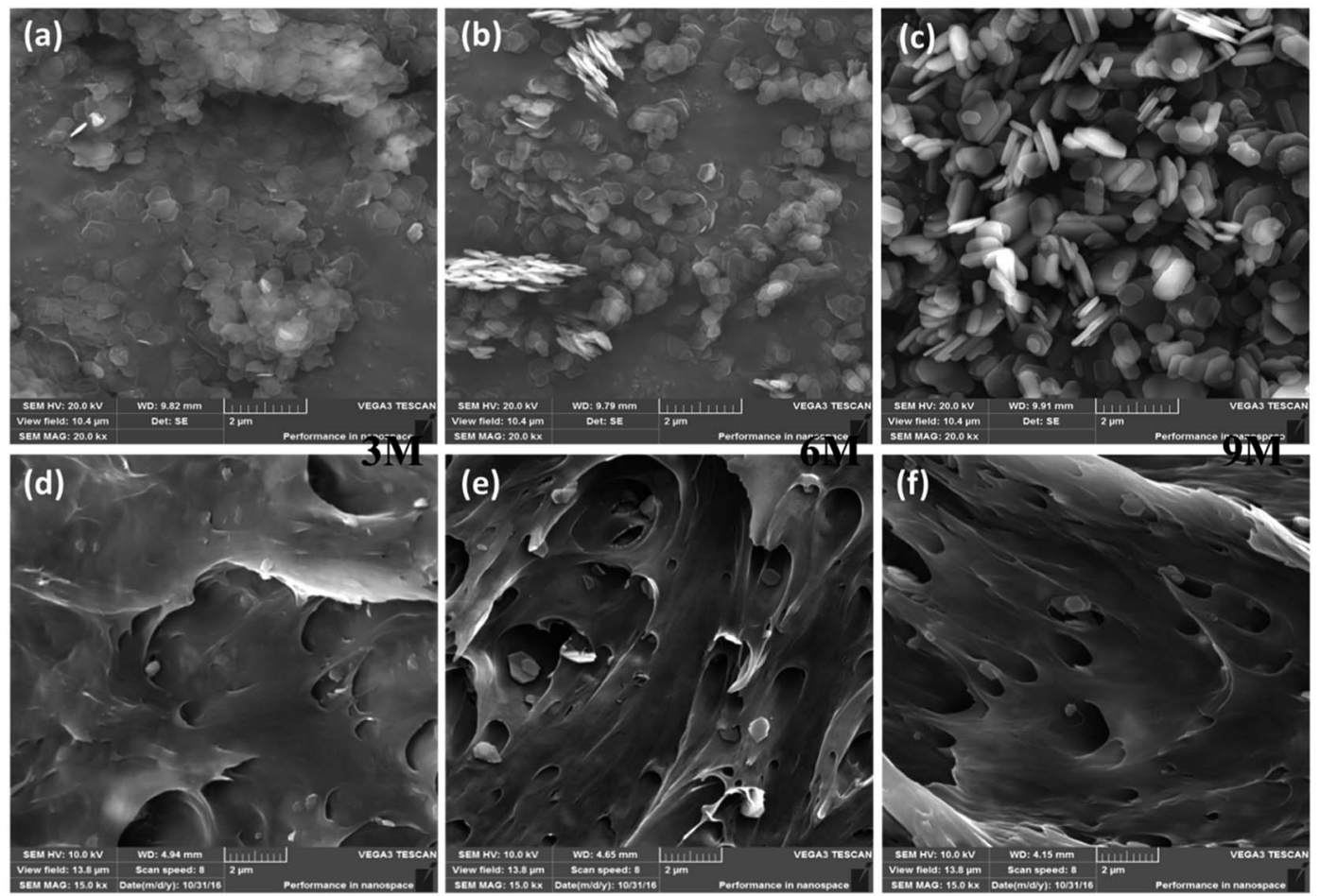

Fig. 1 SEM images of (a) 3MZrP, (b) 6MZrP, (c) 9MZrP, (d) 3 M 5\% ZrP Nylon nanocomposites (e) 6 M 5\% ZrP Nylon nanocomposites and (f) 9 M 5\% ZrP Nylon nanocomposites. 

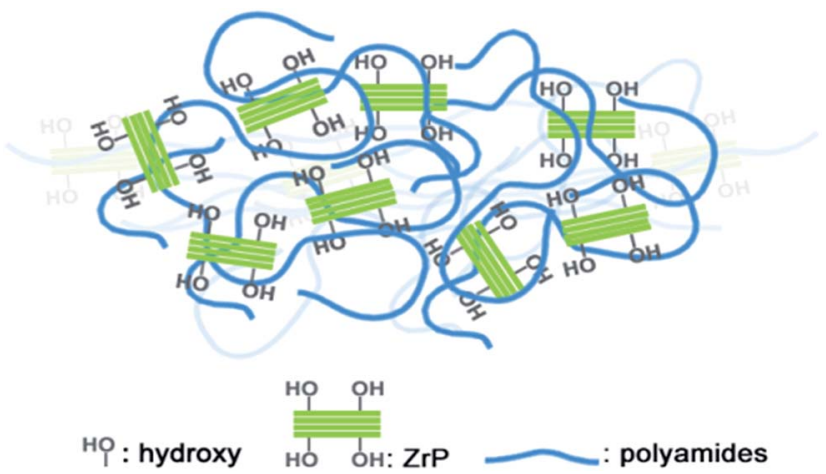

Fig. 3 Schematic of pristine ZrP nanoplatelet dispersion into the Nylon6 matrix.

compatibility between the pristine $\mathrm{ZrP}$ nanoplatelets and Nylon6 polymer chains, as is illustrated in Fig. 3. The Nylon6 contains thermoplastic polyamide chains with a relatively high density of polar groups, while the pristine ZrP nanoplatelets are heavily covered with hydroxyl groups. Even though the Nylon6 polymer chains cannot intercalate/exfoliate the ZrP nanoplatelets without using surfactants due to their large molecular sizes and the strong adhesion in between the pristine layers by hydrogen bonding, the affinity of the ZrP nanoplatelets surface polar groups to the polyamides is still large enough to ensure the good dispersion of the pristine ZrP nanoplatelets into the molten Nylon6 under shear stress. It is expected that by using proper intercalation agents, the exfoliation of ZrP nanoplatelets into Nylon 6 by melt processing could be realized like the case of polymer/organoclay nanocomposites ${ }^{39}$ and epoxy/ZrP nanocomposites with Jeffamines, which will be the focus of our future exploration. Anyway, in the current study the good dispersion of pristine ZrP nanoplatelets into Nylon6 by melt compounding has been realized at ease, and thus the systematical investigation on the mechanical properties of such polymer nanocomposites can be achieved.

\subsection{Mechanical properties}

3.2.1. Tensile testing. The tensile stress-strain curves for the neat Nylon6 and Nylon6 nanocomposites containing various pristine $\mathrm{ZrP}$ nanoplatelets with different concentrations are presented in Fig. $4 \mathrm{a}-\mathrm{c}$. The results of tensile modulus and tensile strength for all these samples are displayed together in Fig. $4 \mathrm{~d}$ for the purpose of comparison. The above data as well as the elongations at break for all the samples are also summarized in Table 2. It is clear from the tensile results that with the incorporation of pristine ZrP nanoplatelets, Nylon6/ZrP nanocomposites show a considerable enhancement in tensile modulus and a limited increase in tensile strength along with a reduction in elongation at break as compared to the neat Nylon6, which is mainly due to the presence of inorganic nanoplatelets as reinforcing fillers. The phenomenon that the increase of modulus and strength is compromised by the decrease of ductility is frequently observed by adding different inorganic fillers into polymer matrices such as carbon
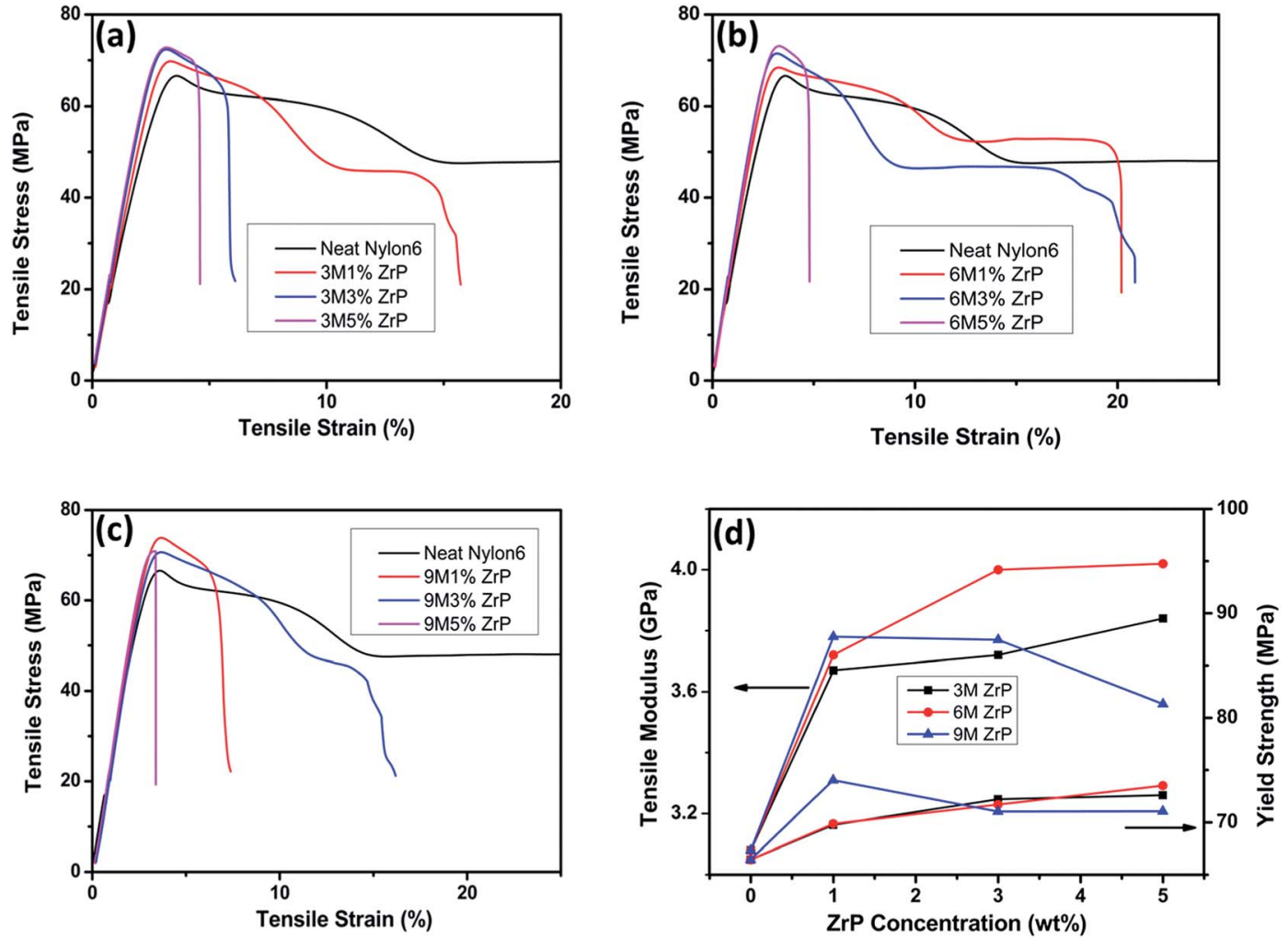

Fig. 4 Tensile stress-strain curves of the neat Nylon6 and the Nylon6 nanocomposites containing (a) 3MZrP, (b) 6MZrP, and (c) 9MZrP nanoplatelets. (d) Tensile modulus and strength of various Nylon6/ZrP nanocomposites as a function of the filler concentration. 
Table 2 Summary of mechanical properties of neat Nylon6 and its nanocomposites

\begin{tabular}{llll}
\hline & $\begin{array}{l}\text { Tensile } \\
\text { modulus } \\
(\mathrm{GPa})\end{array}$ & $\begin{array}{l}\text { Yield } \\
\text { strength } \\
(\mathrm{MPa})\end{array}$ & $\begin{array}{l}\text { Elongation at break } \\
\text { (\%) crosshead speed: } \\
\text { 20 } \mathrm{mm} \mathrm{min}^{-1}\end{array}$ \\
\hline PA6 & 3.08 & 66.44 & 124.86 \\
3 M 1.0 wt\% ZrP & 3.67 & 69.76 & 15.72 \\
3 M 3.0 wt\% ZrP & 3.72 & 72.20 & 6.07 \\
3 M 5.0 wt\% ZrP & 3.84 & 72.59 & 4.59 \\
6 M 1.0 wt\% ZrP & 3.72 & 69.86 & 20.21 \\
6 M 3.0 wt\% ZrP & 4.00 & 71.69 & 20.90 \\
6 M 5.0 wt\% ZrP & 4.02 & 73.50 & 4.81 \\
9 M 1.0 wt\% ZrP & 3.78 & 74.03 & 7.35 \\
9 M 3.0 wt\% ZrP & 3.77 & 71.02 & 16.14 \\
9 M 5.0 wt\% ZrP & 3.56 & 71.04 & 3.40 \\
& & & \\
\hline
\end{tabular}

nanotubes ${ }^{40}$ and various types of clays including untreated, intercalated, and exfoliated MMT. ${ }^{18}$

With the incorporation of only $1.0 \%$ of pristine ZrP nanoplatelets in Nylon6, 3 M 1\% ZrP, 6 M 1\% ZrP, and 9 M 1\% ZrP Nylon6 nanocomposites all experience a large increase in tensile modulus by $\sim 19 \%, \sim 21 \%$, and $\sim 23 \%$ and tensile strength by $\sim 5 \%, \sim 7 \%$, and $\sim 11 \%$, respectively as compared to the neat Nylon6. The larger the size of the pristine ZrP nanoplatelets incorporated is, the higher the tensile modulus and strength become for the Nylon6/ZrP nanocomposites at a low filler concentration. When the concentration of $\mathrm{ZrP}$ nanoplatelets in Nylon6 is increased to $3 \%$ and $5 \%$, however, the change on the tensile properties for the Nylon6 nanocomposites varies with the size of the pristine $\mathrm{ZrP}$ nanoplatelets incorporated. The Nylon6/3MZrP nanocomposites show a steady change in tensile behaviors as the concentration of the pristine $\mathrm{ZrP}$ nanoplatelets increases. For example, the tensile modulus for Nylon6 nanocomposites with $1 \%, 3 \%$ and $5 \%$ of $3 \mathrm{MZrP}$ nanoplatelets show a continuing increase of $\sim 19 \%, \sim 21 \%$ and $\sim 25 \%$, respectively, as compared to the neat Nylon6. When $3 \%$ of $6 \mathrm{MZrP}$ nanoplatelets are added into Nylon6, the tensile modulus of such nanocomposites becomes $4.00 \mathrm{GPa}, \sim 30 \%$ increase as compared to the neat Nylon 6 with a tensile modulus of $3.08 \mathrm{GPa}$, which is also larger than the Nylon6 nanocomposites with $3 \%$ of $3 \mathrm{MZrP}$ nanoplatelets. However, a further increase in the concentration of 6MZrP nanoplatelets in Nylon6 to $5 \%$ leads only to a very small increase in tensile modulus to around 4.02 $\mathrm{GPa}$ as compared to the $6 \mathrm{M} \mathrm{3 \%} \mathrm{ZrP}$ Nylon6 nanocomposites with a tensile modulus of $4.00 \mathrm{GPa}$. As for the Nylon6 nanocomposites containing 9MZrP nanoplatelets, the increase of the filler concentration to $3 \%$ results in an unexpected slight decrease in tensile modulus as compared to the $9 \mathrm{M} 1 \% \mathrm{ZrP}$ nanocomposites, which is even lower than that of the $6 \mathrm{M} \mathrm{3 \%} \mathrm{ZrP}$ nanocomposites, but still higher than that of the $3 \mathrm{M} \mathrm{3 \%} \mathrm{ZrP}$ nanocomposites. A further increase in the concentration of 9MZrP nanoplatelets in Nylon6 to 5\% significantly decreases the tensile modulus of the nanocomposites, which is the lowest among all the Nylon6/ZrP nanocomposites prepared in the current study. The overall enhancement in tensile strength for the nanocomposites containing various pristine $\mathrm{ZrP}$ nanoplatelets is limited as compared to the neat Nylon6. The tensile strengths of the Nylon6 nanocomposites containing $3 \mathrm{MZrP}$ and $6 \mathrm{MZrP}$ nanoplatelets gradually increase as the increase of the filler concentration. However, the 9 M 3\% ZrP and 9 M 5\% ZrP Nylon6 nanocomposites show a similar tensile strength, which is even lower than that of the $9 \mathrm{M} 1 \% \mathrm{ZrP}$ nanocomposites. The highest tensile strength obtained in the current study is about 73-74 MPa for the $6 \mathrm{M} \mathrm{5 \%} \mathrm{ZrP} \mathrm{and} 9 \mathrm{M}$ $1 \% \mathrm{ZrP}$ nanocomposites, only $\sim 11 \%$ higher than that of the neat Nylon6. By comparing the tensile properties of all the nanocomposite samples including modulus, strength, and elongation at break as listed in Table 2, the $6 \mathrm{M} 3 \% \mathrm{ZrP}$ nanocomposites exhibit the best performance with a tensile modulus of $\sim 4.00 \mathrm{GPa}$, a tensile strength of $\sim 71.69 \mathrm{MPa}$, and an elongation at break of $\sim 20.90 \%$.

The above results suggest that to be able to achieve a good tensile behavior of Nylon6 by melt compounding with pristine ZrP nanoplatelets, both size and concentration of the fillers should be balanced and that in the current study pristine $\mathrm{ZrP}$ nanoplatelets of around $600-800 \mathrm{~nm}$ by hydrothermal synthesis in $6 \mathrm{M}$ phosphoric acid are the best to improve the tensile properties of Nylon6 with a filler concentration of around 3.0$5.0 \%$. The literature reports on Nylon6/clay nanocomposites have shown that around $5 \%$ of unmodified montmorillonites in Nylon6 can only lead to a small increase of around $10 \%$ in tensile modulus and that the use of organoclays can result in a better dispersion of the fillers and thus a higher increase in tensile modulus of around $30 \%{ }^{1,18}$ However, in our current study, the Nylon6 nanocomposites containing $3.0 \%$ of $6 \mathrm{MZrP}$ nanoplatelets without any surface modification show $\sim 30 \%$ increase in tensile modulus as compared to the neat Nylon6, indicating that $\mathrm{ZrP}$ nanoplatelets are superior for melt mixing with Nylon6 for mechanical reinforcement.

The tensile properties of polymer nanocomposites containing inorganic nanoplatelets strongly depend on both the size and concentration of the fillers. The nanoplatelet concentration effect in various polymers has been widely discussed in the literature. In general, the higher the nanoplatelet (i.e. clays) concentration is, the larger the tensile modulus and strength become for the polymer nanocomposites with a relatively good filler dispersion. On the other hand, the nanoplatelet size effect is less studied probably due to the lack of a good practical system for systematical investigations especially in the thermoplastic polymers like Nylon by melt compounding method. The effects of size, concentration, and dispersion of ZrP nanoplatelets on the mechanical properties of thermosetting epoxy by solution mixing have be well investigated in a series of publications lead by H. J. Sue. ${ }^{41,42}$ Generally, the higher the concentration and the larger the size of the $\mathrm{ZrP}$ nanoplatelets is, the higher the tensile modulus and strength and the smaller the ductility are for the epoxy/ZrP nanocomposites. ${ }^{43}$ The observed difference in the tensile behavior as a function of nanoplatelet size and concentration between the Nylon6/ZrP nanocomposites in the current study and the epoxy/ZrP nanocomposites in the literature might be due largely to their different nature of the polymer matrices. The epoxy matrices, 
once cured, are networked molecules while Nylon is thermoplastic with entangled polymer chains and partially crystallized domains. Therefore, the mechanisms that are responsible for reinforcing the thermosetting matrices by $\mathrm{ZrP}$ nanoplatelets should be different from those for the thermoplastic polymers. First, the flow and deformation behaviors between a thermosetting epoxy and a thermoplastic Nylon under the tensile test are different. As a result, the change on the mechanical properties of two different types of polymer matrices as a function of the size and concentration of the incorporated pristine $\mathrm{ZrP}$ nanoplatelets should be varied, especially for the large-sized samples such as our $6 \mathrm{MZrP}$ and $9 \mathrm{MZrP}$ nanoplatelets. In addition, the effect of each individual nanoplatelets embedded in the polymer nanocomposites on their surrounding areas is different with different polymer matrices. The thermosetting epoxy networks are usually rigid, thus are less affected by the adjacent inorganic nanoplatelets as compared to the relatively flexible thermoplastic polymer chains especially at the temperature lower than $T_{\mathrm{g}}$. This can be validated by the DMA results in our following study.

3.2.2. Dynamical mechanical analysis. Fig. 5a-c show the storage modulus as a function of temperature ranging from $-50{ }^{\circ} \mathrm{C}$ to $200{ }^{\circ} \mathrm{C}$ for all the Nylon6/ZrP nanocomposites and the neat Nylon6 from the DMA measurements under the frequency of $1.0 \mathrm{~Hz}$. The storage moduli at the representative temperatures of $-25{ }^{\circ} \mathrm{C}$ (lower than $T_{\mathrm{g}}$ ) and $125^{\circ} \mathrm{C}$ (higher than $T_{\mathrm{g}}$ ) for the neat Nylon6 and its nanocomposites are presented in Fig. 5d and e, respectively. The corresponding DMA data are also summarized in Table 3. Compared with the neat Nylon6, the storage modulus of the nanocomposites undergoes a significant improvement owing to the incorporation of the nanoplatelets into the polymer matrices, indicating that pristine $\mathrm{ZrP}$ nanoplatelets embedded have a strong reinforcing impact on the dynamic elastic behavior of Nylon6.

In both the glassy region (in the temperature range lower than $T_{\mathrm{g}}$ ) and the rubbery plateau (in the temperature range higher than $T_{\mathrm{g}}$ ), the storage modulus as a function of the nanoplatelet size behaves differently for the nanocomposites with various filler concentrations, especially for the larger-sized ZrP nanoplatelets at a relatively higher concentration. The storage modulus for the Nylon6/ZrP nanocomposites with 1.0\% of the filler concentration exhibits a steady increase with increasing the size of the incorporated pristine $\mathrm{ZrP}$ nanoplatelets at both $-25{ }^{\circ} \mathrm{C}$ and $125{ }^{\circ} \mathrm{C}$. In specific, as compared with the neat Nylon6, there is an increment of $\sim 15 \%, \sim 29 \%$, and $\sim 49 \%$ in storage modulus at $-25{ }^{\circ} \mathrm{C}$ with regard to the $3 \mathrm{M}$ $1.0 \mathrm{wt} \% \mathrm{ZrP}, 6 \mathrm{M} 1.0 \mathrm{wt} \% \mathrm{ZrP}$, and $9 \mathrm{M} 1.0 \mathrm{wt} \% \mathrm{ZrP}$ nanocomposites, respectively. At the same time, the corresponding increases in storage modulus at $125{ }^{\circ} \mathrm{C}$ are $\sim 18 \%, 35 \%$, and $\sim 41 \%$. The change on the storage modulus of the Nylon6/ZrP
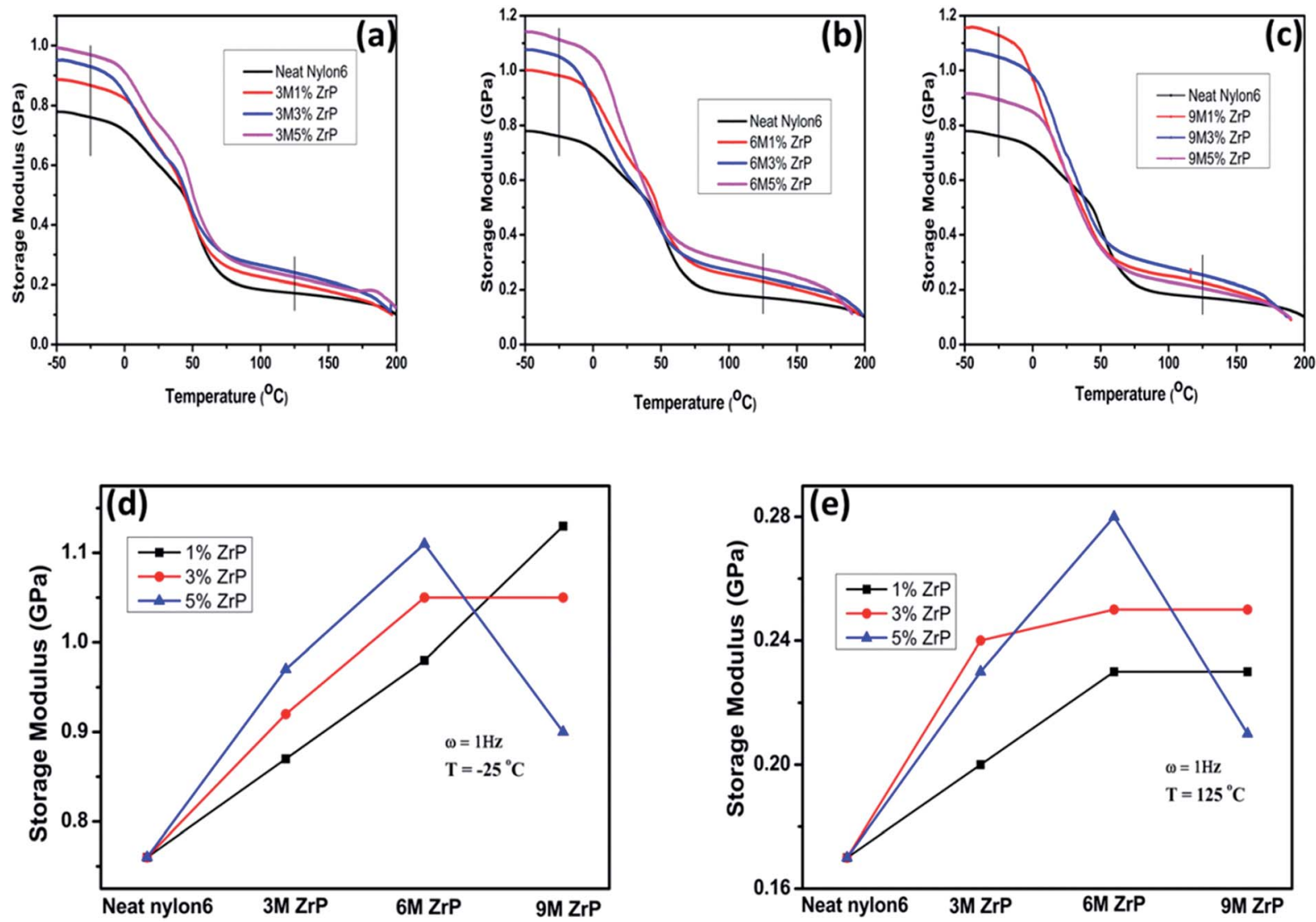

Fig. 5 Temperature-dependent storage modulus for the Nylon6 nanocomposites containing (a) 3MZrP, (b) 6MZrP, and (c) 9MZrP nanoplatelets at various concentrations $\left(1.0 \mathrm{~Hz}\right.$ ). The measured storage modulus at temperature of $-25^{\circ} \mathrm{C}$ (d) and $125^{\circ} \mathrm{C}$ (e) for the Nylon6 nanocomposites. 
nanocomposites at the filler concentration of $3.0 \mathrm{wt} \%$ with increasing the size of the nanoplatelets incorporated is similar to that of the Nylon6/ZrP nanocomposites at $1.0 \mathrm{wt} \%$. Besides, the overall storage modulus of the Nylon6/ZrP nanocomposites at $3.0 \mathrm{wt} \%$ is higher than that of the Nylon6/ZrP nanocomposites at $1.0 \mathrm{wt} \%$ for the corresponding nanoplatelet size at both representative temperatures, except for the nanocomposites containing the $9 \mathrm{MZrP}$ nanoplatelets at $-25{ }^{\circ} \mathrm{C}$, where the storage modulus of the 9 M 3.0 wt\% ZrP nanocomposites is lower than that of the $9 \mathrm{M} 1.0 \mathrm{wt} \% \mathrm{ZrP}$ nanocomposites. As for the Nylon6/ZrP nanocomposites at $5.0 \mathrm{wt} \%$, the increase of the size of the incorporated nanoplatelets from $3 \mathrm{MZrP}$ to $6 \mathrm{MZrP}$ leads to the enhancement in the storage modulus at the temperatures both below and above $T_{\mathrm{g}}$. However, the further increase of the nanoplatelet size to 9MZrP results in a significant drop in storage modulus at both representative temperatures, which is not only lower than those of the $6 \mathrm{M} 5.0 \mathrm{wt} \% \mathrm{ZrP}$ and $3 \mathrm{M} 5.0 \mathrm{wt} \% \mathrm{ZrP}$ nanocomposites, but also even smaller than those of the $9 \mathrm{M} 3.0 \mathrm{wt} \% \mathrm{ZrP}$ and $9 \mathrm{M} 1.0$ wt\% ZrP nanocomposites.

By considering both the above DMA and tensile results, it is suggested that to obtain good mechanical properties of Nylon6 nanocomposites by melt compounding with pristine $\mathrm{ZrP}$ nanoplatelets, both the size and concentration of the nanofillers should be carefully considered and that based on the current study, the pristine ZrP nanoplatelets of around 600$800 \mathrm{~nm}$ by the hydrothermal synthesis in $6 \mathrm{M}$ phosphoric acid are probably optimal for improving the mechanical performances of the corresponding Nylon6 nanocomposites at a nanofiller concentration of around 3.0-5.0\%. According to the molecular dynamics simulation ${ }^{44}$ as well as the experimental analysis ${ }^{\mathbf{4 1}}$ on the nanofiller effect on the mechanical properties of polymer nanocomposites, both the dimension and mobility of the embedded nanofillers have profound influences on boosting the stiffness of the polymer matrices. The excellent mobility of the nanofillers with smaller sizes helps to enhance the stiffness of the polymer matrices by efficiently carrying and redistributing more stress fields introduced. On the other hand, even though the embedded nanofillers with larger sizes could bear more surrounding tensions, their local movements in the

Table 3 Summary of DMA test for Nylon6 and various Nylon6/ZrP under different temperature range

\begin{tabular}{llll}
\hline & \multicolumn{2}{l}{ Storage modulus (GPa) } & \\
\cline { 2 - 3 } Samples & $-25{ }^{\circ} \mathrm{C}$ & $125{ }^{\circ} \mathrm{C}$ & $T_{\mathrm{g}}\left({ }^{\circ} \mathrm{C}\right)$ \\
\hline Nylon6 & 0.76 & 0.17 & 59.4 \\
3 M 1.0 wt\% ZrP & 0.87 & 0.20 & 55.5 \\
3 M 3.0 wt\% ZrP & 0.93 & 0.24 & 54.2 \\
3 M 5.0 wt\% ZrP & 0.97 & 0.23 & 57.0 \\
6 M 1.0 wt\% ZrP & 0.98 & 0.23 & 55.9 \\
6 M 3.0 wt\% ZrP & 1.05 & 0.25 & 54.9 \\
6 M 5.0 wt\% ZrP & 1.11 & 0.28 & 47.4 \\
9 M 1.0 wt\% ZrP & 1.13 & 0.24 & 48.7 \\
9 M 3.0 wt\% ZrP & 1.05 & 0.26 & 44.5 \\
9 M 5.0 wt\% ZrP & 0.90 & 0.20 & 40.3
\end{tabular}

polymer matrices under stress fields would, to some extent, be restricted. Therefore, it appears that there should be an optimal size range for the embedded nanofillers in which the mechanical improvements for the polymer matrices could be maximized. This explains our experimental observation that the $6 \mathrm{MZrP}$ nanoplatelets with their size ranging in between all the pristine ZrP nanoplatelets studied are the optimal in terms of enhancing the mechanical properties of Nylon6 in a specific concentration range. Furthermore, as compared to the 9MZrP nanoplatelets, the $3 \mathrm{MZrP}$ and $6 \mathrm{MZrP}$ nanoplatelets are smaller in size, suggesting that they are likely to be more mobile in the Nylon6 matrices under external stress fields so that their respective moduli show a more obvious gradual incensement as the increase of the nanoplatelet concentration, especially for the smallest pristine nanoplatelets of $3 \mathrm{MZrP}$. At the same time, the $6 \mathrm{MZrP}$ nanoplatelets are larger than the $3 \mathrm{MZrP}$ nanoplatelets in size. When incorporated into Nylon6, the former exhibits a larger reinforcement in the mechanical properties to the polymer matrices than the later, resulting more likely from the greater contributions from the effects of their relatively larger size. When the size of the embedded nanoplatelets increases to 9MZrP, however, the reduced modulus of the corresponding nanocomposites especially at a relatively high nanofiller concentration is mainly due to the extremely restricted mobility of such large nanoplatelets in Nylon under external stress fields.

The DMA results shown in Fig. 6 also elucidate an interesting phenomenon that at the temperatures both below and above $T_{\mathrm{g}}$, the storage moduli of the Nylon6/ZrP nanocomposites have been considerably increased together as compared to the neat Nylon6 especially for the Nylon6/3MZrP and Nylon6/6MZrP nanocomposites, which is different from the epoxy/ZrP nanocomposites reported in the literature. For typical thermosetting epoxy $^{\mathbf{4 5}}$ nanocomposites containing ZrP nanoplatelets, ${ }^{\mathbf{4 3}}$ the rubbery plateau modulus is increased as the increase of the nanofiller concentration while the storage modulus in the glassy region usually retains similar to the neat epoxy. Similar phenomenon has also been observed in the epoxy/graphene nanocomposites. ${ }^{\mathbf{4}}$ The reason is due to the rigid nature of the molecular networks in the thermosetting epoxy matrices. In the temperature range below $T_{\mathrm{g}}$, the solid epoxy networks significantly confine the mobility of the embedded nanoplatelets leading to a minimal stiffening effect under the dynamic mechanical testing. However, for the nanocomposites with thermoplastic matrices like Nylon6, the polymer chains, even though in their glassy state, would not restrict the motion of the embedded nanoplatelets as much as the epoxy networks especially under external stress fields, thus leading to an obvious improvement in the storage modulus.

In fact, in the case of our Nylon6/ZrP nanocomposites, the pristine ZrP nanoplatelets could increase the flexibility of the surrounding polymer chains, which can, in turn, facilitate the motion of the nanoplatelets themselves under external stress fields. This could be verified by the change of the $T_{\mathrm{g}}$ as a function of the nanoplatelet size and concentration as illustrated in Fig. 6. In general, the larger the size and the higher the nanoplatelet concentration is, the lower the $T_{\mathrm{g}}$ is for the 

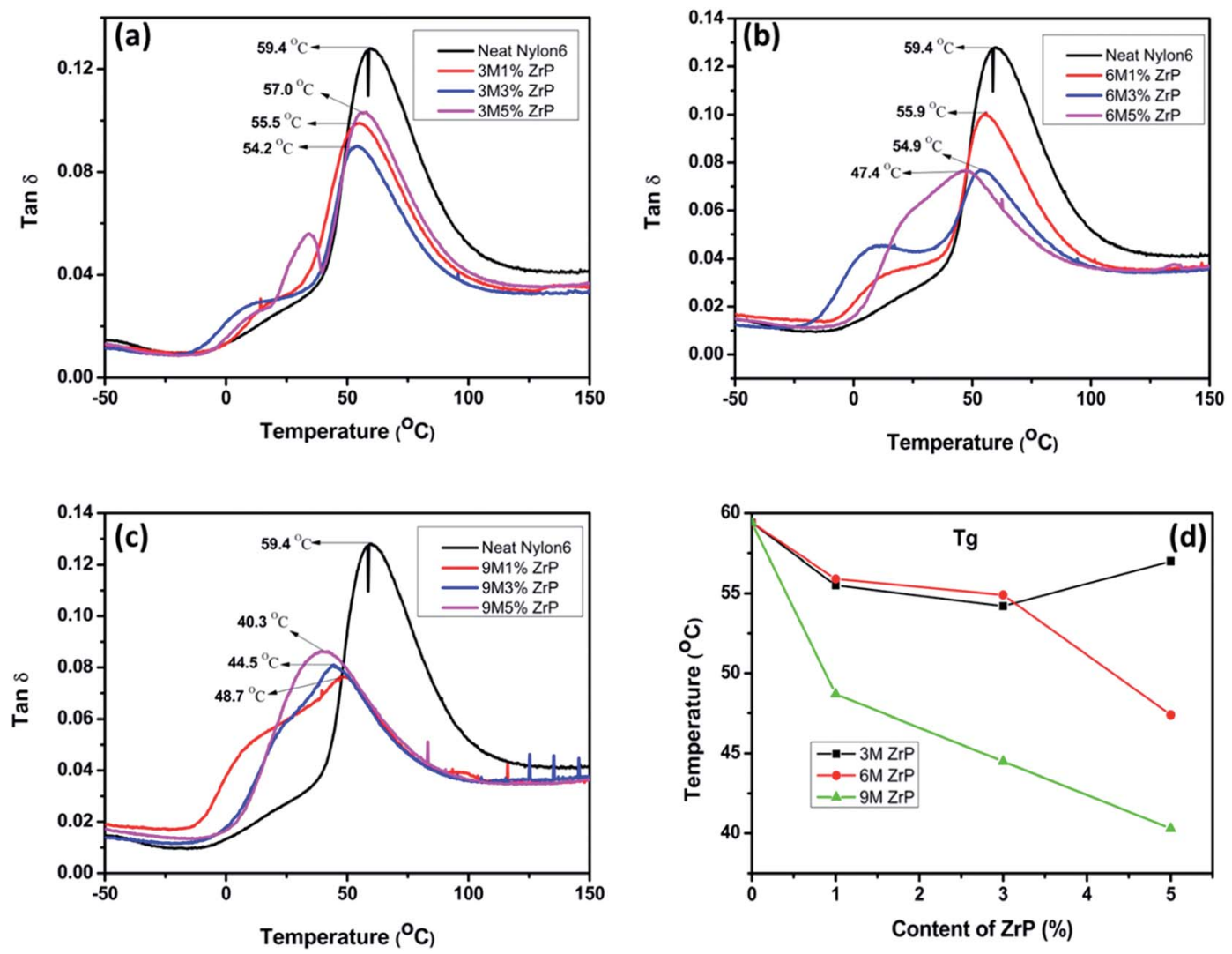

Fig. $6 \tan \delta$ for Nylon6/ZrP nanocomposites containing (a) 3MZrP; (b) 6MZrP; and (c) 9MZrP nanoplatelets as a function of temperature at the frequency of $1.0 \mathrm{~Hz}$. (d) $T_{\mathrm{g}}$ of the neat Nylon 6 and the nanocomposites determined from DMA.

nanocomposites as measured from the DMA tan $\delta$-temperature curves. The reduced $T_{\mathrm{g}}$ and the observed broadening of the glass transition peaks for the nanocomposites as shown in Fig. 6 are a good illustration on the increased flexibility of the Nylon6 matrices by the incorporation of our pristine $\mathrm{ZrP}$ nanoplatelets. This result is completely different from the previous reports on Nylon6/clay, ${ }^{47}$ PMMA (polymethyl methacrylate)/carbon nanotube ${ }^{48}$ and EVA/MMT ${ }^{49}$ nanocomposites, in which the increased $T_{\mathrm{g}}$ for the polymer nanocomposites is mainly resulted from the restricted mobility of the polymer chains by adding various nanofillers. Herein, the possible reason for our observations is that the pristine $\mathrm{ZrP}$ nanoplatelets possess excellent lubricating properties, ${ }^{50}$ and are thus likely to help increase the mobility and flexibility of the surrounding polymer chains in Nylon6. The detailed studies on the role of the pristine $\mathrm{ZrP}$ nanoplatelets in polymer nanocomposites as well as their effect on the crystallization behaviors of Nylon6 are under way and will be reported in the future.

\section{Conclusion}

In summary, we have systematically investigated the mechanical properties of the Nylon6 nanocomposites containing pristine $\mathrm{ZrP}$ nanoplatelets with various sizes. The size of the $\mathrm{ZrP}$ nanoplatelets ranging from $\sim 200 \mathrm{~nm}$ to $\sim 1 \mu \mathrm{m}$ was controlled by tuning the concentration of phosphoric acid during the hydrothermal synthesis. The pristine $\mathrm{ZrP}$ nanoplatelets were incorporated into Nylon6 by a melt-compounding method without adding any surfactant. The SEM images and XRD patterns of the nanocomposites show that the pristine $\mathrm{ZrP}$ nanoplatelets have been well dispersed into the Nylon6 matrices without changing their crystalline structures during the melting process due to the excellent compatibility between the pristine ZrP nanoplatelets and the Nylon6 polymer chains. The mechanical characterizations based on tensile and DMA measurements suggest that pristine $\mathrm{ZrP}$ nanoplatelets with a large size and relatively high concentration would result in a significant reduction to the mechanical performance of the Nylon6 nanocomposites and that an optimal reinforcing improvement for Nylon 6 can be achieved by adding pristine ZrP nanoplatelets of around $600-800 \mathrm{~nm}$ in size with a concentration of about $3.0-5.0 \%$. The enhanced mechanical properties of the Nylon6/ZrP nanocomposites are attributed to the increased mobility of the embedded nanofillers in the thermoplastic matrices both below and above $T_{\mathrm{g}}$. Our study demonstrates the possibility of utilizing pristine $\mathrm{ZrP}$ nanoplatelets to prepare polymer nanocomposites by melt processing at low cost and would be of great benefit to design and fabricate reinforced engineering thermoplastics with desired properties.

\section{Acknowledgements}

This work was supported by the start-up funding from Southern University of Science and Technology (SUSTech) and "The 
Recruitment Program of Global Youth Experts of China”, the Foundation of Shenzhen Science and Technology Innovation Committee (Grant No. ZDSYS20140509142721431, JCYJ20160315164631204, and KQTD20140630110339343), and NSFC-21306077. X. H. acknowledges the "Innovation and Entrepreneurship Training Funding for Undergraduates" from SUSTech. H. Z. thanks Jiaxin Wang for the helpful discussions.

\section{References}

1 D. R. Paul and L. M. Robeson, Polymer nanotechnology: nanocomposites, Polymer, 2008, 49(15), 3187-3204.

2 C. Sanchez, B. Julian, P. Belleville and M. Popall, Applications of hybrid organic-inorganic nanocomposites, J. Mater. Chem., 2005, 15(35-36), 3559-3592.

3 S. S. Ray and M. Okamoto, Polymer/layered silicate nanocomposites: a review from preparation to processing, Prog. Polym. Sci., 2003, 28(11), 1539-1641.

4 E. P. Giannelis, Polymer layered silicate nanocomposites, Adv. Mater., 1996, 8(1), 29-35.

5 P. C. LeBaron, Z. Wang and T. J. Pinnavaia, Polymer-layered silicate nanocomposites: an overview, Appl. Clay Sci., 1999, 15(1-2), 11-29.

$6 \mathrm{M}$. Alexandre and P. Dubois, Polymer-layered silicate nanocomposites: preparation, properties and uses of a new class of materials, Mater. Sci. Eng., R, 2000, 28(1-2), 1-63.

7 S. Pavlidou and C. D. Papaspyrides, A review on polymerlayered silicate nanocomposites, Prog. Polym. Sci., 2008, 33(12), 1119-1198.

8 E. P. Giannelis, Polymer-layered silicate nanocomposites: synthesis, properties and applications, Appl. Organomet. Chem., 1998, 12(10-11), 675-680.

9 E. M. Reyes-Gallardo, R. Lucena and S. Cárdenas, Silica nanoparticles-Nylon 6 composites: synthesis, characterization and potential use as sorbent, RSC Adv., 2017, 7(4), 2308-2314.

10 E. M. Reyes-Gallardo, R. Lucena, S. Cárdenas and M. Valcárcel, Dispersive micro-solid phase extraction of bisphenol A from milk using magnetic Nylon 6 composite and its final determination by HPLC-UV, Microchem. J., 2016, 124, 751-756.

11 F. Hussain, M. Hojjati, M. Okamoto and R. E. Gorga, Review article: Polymer-matrix nanocomposites, processing, manufacturing, and application: an overview, J. Compos. Mater., 2006, 40(17), 1511-1575.

12 L. F. Cai, Z. Y. Lin and H. Qian, Dispersion of nano-silica in monomer casting Nylon6 and its effect on the structure and properties of composites, eXPRESS Polym. Lett., 2010, 4(7), 397-403.

13 T. Jiang, Y. H. Wang, J. T. Yeh and Z. Q. Fan, Study on solvent permeation resistance properties of Nylon6/clay nanocomposite, Eur. Polym. J., 2005, 41(3), 459-466.

14 C. X. Zhao, P. Li, D. He, Y. T. Li, F. Lei and H. J. Sue, Flame retardation behavior of polybenzoxazine/alpha-ZrP nanocomposites, RSC Adv., 2016, 6(77), 73485-73495.

15 F. Laoutid, L. Bonnaud, M. Alexandre, J. M. Lopez-Cuesta and P. Dubois, New prospects in flame retardant polymer materials: from fundamentals to nanocomposites, Mater. Sci. Eng., R, 2009, 63(3), 100-125.

16 P. Kiliaris and C. D. Papaspyrides, Polymer/layered silicate (clay) nanocomposites: an overview of flame retardancy, Prog. Polym. Sci., 2010, 35(7), 902-958.

17 S. C. Tjong, Structural and mechanical properties of polymer nanocomposites, Mater. Sci. Eng., R, 2006, 53(3-4), 73-197.

$18 \mathrm{~J}$. W. Cho and D. R. Paul, Nylon 6 nanocomposites by melt compounding, Polymer, 2001, 42(3), 1083-1094.

19 T. D. Fornes and D. R. Paul, Modeling properties of Nylon 6/ clay nanocomposites using composite theories, Polymer, 2003, 44(17), 4993-5013.

20 T. D. Fornes, P. J. Yoon, H. Keskkula and D. R. Paul, Nylon 6 nanocomposites: the effect of matrix molecular weight, Polymer, 2001, 42(25), 9929-9940.

21 R. Krishnamoorti, R. A. Vaia and E. P. Giannelis, Structure and dynamics of polymer-layered silicate nanocomposites, Chem. Mater., 1996, 8(8), 1728-1734.

22 L. M. Liu, Z. N. Qi and X. G. Zhu, Studies on Nylon 6 clay nanocomposites by melt-intercalation process, J. Appl. Polym. Sci., 1999, 71(7), 1133-1138.

23 P. Li, K. L. White, C.-H. Lin, D. Kim, A. Muliana, R. Krishnamoorti, R. Nishimura and H.-J. Sue, Mechanical reinforcement of epoxy with self-assembled synthetic clay in smectic order, ACS Appl. Mater. Interfaces, 2014, 6(13), 10188-10195.

24 P. B. Messersmith and E. P. Giannelis, Synthesis and characterization of layered silicate-epoxy nanocomposites, Chem. Mater., 1994, 6(10), 1719-1725.

25 T. Lan and T. J. Pinnavaia, Clay-reinforced epoxy nanocomposites, Chem. Mater., 1994, 6(12), 2216-2219.

26 X. Fu and S. Qutubuddin, Polymer-clay nanocomposites: exfoliation of organophilic montmorillonite nanolayers in polystyrene, Polymer, 2001, 42(2), 807-813.

27 T. Lan, P. D. Kaviratna and T. J. Pinnavaia, Mechanism of clay tactoid exfoliation in epoxy-clay nanocomposites, Chem. Mater., 1995, 7(11), 2144-2150.

$28 \mathrm{~J}$. Marini and R. E. S. Bretas, Influence of shape and surface modification of nanoparticle on the rheological and dynamic-mechanical properties of polyamide 6 nanocomposites, Polym. Eng. Sci., 2013, 53(7), 1512-1528.

29 R. A. Vaia, K. D. Jandt, E. J. Kramer and E. P. Giannelis, Microstructural evolution of melt intercalated polymerorganically modified layered silicates nanocomposites, Chem. Mater., 1996, 8(11), 2628-2635.

30 L. Sun, W. J. Boo, D. Sun, A. Clearfield and H.-J. Sue, Preparation of exfoliated epoxy/ $\alpha$-zirconium phosphate nanocomposites containing high aspect ratio nanoplatelets, Chem. Mater., 2007, 19(7), 1749-1754.

31 N. Sheng, M. C. Boyce, D. M. Parks, G. C. Rutledge, J. I. Abes and R. E. Cohen, Multiscale micromechanical modeling of polymer/clay nanocomposites and the effective clay particle, Polymer, 2004, 45(2), 487-506.

32 Z. Rui, H. Yuan and S. L. Wang, Organically modification of layered alpha-zirconium phosphate, Rare Met. Mater. Eng., 2006, 35, 100-103. 
33 D. M. Kaschak, S. A. Johnson, D. E. Hooks, H. N. Kim, M. D. Ward and T. E. Mallouk, Chemistry on the edge: a microscopic analysis of the intercalation, exfoliation, edge functionalization, and monolayer surface tiling reactions of alpha-zirconium phosphate, J. Am. Chem. Soc., 1998, 120(42), 10887-10894.

34 L. Y. Sun, W. J. Boo, H. J. Sue and A. Clearfield, Preparation of alpha-zirconium phosphate nanoplatelets with wide variations in aspect ratios, New J. Chem., 2007, 31(1), 39-43.

$35 \mathrm{~J}$. Alongi and A. Frache, Flame retardancy properties of $\alpha$ zirconium phosphate based composites, Polym. Degrad. Stab., 2010, 95(9), 1928-1933.

36 L. Sun, W. J. Boo, H.-J. Sue and A. Clearfield, Preparation of $\alpha$-zirconium phosphate nanoplatelets with wide variations in aspect ratios, New J. Chem., 2007, 31(1), 39-43.

37 A. Clearfield and J. A. Stynes, The preparation of crystalline zirconium phosphate and some observations on its ion exchange behavior, J. Inorg. Nucl. Chem., 1964, (26), 117-129.

38 M. Shuai, A. F. Mejia, Y.-W. Chang and Z. Cheng, Hydrothermal synthesis of layered $\alpha$-zirconium phosphate disks: control of aspect ratio and polydispersity for nanoarchitecture, CrystEngComm, 2013, 15(10), 1970.

39 P. Reichert, H. Nitz, S. Klinke, R. Brandsch, R. Thomann and R. Mulhaupt, Poly(propylene)/organoclay nanocomposite formation: influence of compatibilizer functionality and organoclay modification, Macromol. Mater. Eng., 2000, 275(2), 8-17.

40 T. X. Liu, I. Y. Phang, L. Shen, S. Y. Chow and W. D. Zhang, Morphology and mechanical properties of multiwalled carbon nanotubes reinforced Nylon-6 composites, Macromolecules, 2004, 37(19), 7214-7222.

41 H. J. Sue, K. T. Gam, N. Bestaoui, N. Spurr and A. Clearfield, Epoxy nanocomposites based on the synthetic alphazirconium phosphate layer structure, Chem. Mater., 2004, 16(2), 242-249.
42 H. J. Sue, K. T. Gam, N. Bestaoui, A. Clearfield, M. Miyamoto and N. Miyatake, Fracture behavior of alpha-zirconium phosphate-based epoxy nanocomposites, Acta Mater., 2004, 52(8), 2239-2250.

43 W. J. Boo, L. Y. Sun, J. Liu, A. Clearfield, H. J. Sue, M. J. Mullins and H. Pham, Morphology and mechanical behavior of exfoliated epoxy/alpha-zirconium phosphate nanocomposites, Compos. Sci. Technol., 2007, 67(2), 262-269.

44 D. Gersappe, Molecular mechanisms of failure in polymer nanocomposites, Phys. Rev. Lett., 2002, 89(5), 058301.

45 N. Salahuddin, A. Moet, A. Hiltner and E. Baer, Nanoscale highly filled epoxy nanocomposite, Eur. Polym. J., 2002, 38(7), 1477-1482.

46 I. Zaman, T. T. Phan, H.-C. Kuan, Q. Meng, L. T. B. La, L. Luong, O. Youssf and J. Ma, Epoxy/graphene platelets nanocomposites with two levels of interface strength, Polymer, 2011, 52(7), 1603-1611.

47 S. B. Xie, S. M. Zhang, F. S. Wang, H. J. Liu and M. S. Yang, Influence of annealing treatment on the heat distortion temperature of Nylon-6/montmorillonite nanocomposites, Polym. Eng. Sci., 2005, 45(9), 1247-1253.

48 M. A. Lopez-Manchado, L. Valentini, J. Biagiotti and J. M. Kenny, Thermal and mechanical properties of singlewalled carbon nano tubes-polypropylene composites prepared by melt processing, Carbon, 2005, 43(7), 14991505.

49 W. Zhang, D. Z. Chen, Q. B. Zhao and Y. Fang, Effects of different kinds of clay and different vinyl acetate content on the morphology and properties of EVA/clay nanocomposites, Polymer, 2003, 44(26), 7953-7961.

50 X. He, H. Xiao, H. Choi, A. Dvaz, B. Mosby, A. Clearfield and H. Liang, $\alpha$-Zirconium phosphate nanoplatelets as lubricant additives, Colloids Surf., A, 2014, 452, 32-38. 